\title{
Effects of Conservation Agriculture and Temperature Sensitivity on Soil Organic Carbon Dynamics; its Fractions, and Soil Aggregate Stability in RWCS of Sub-tropical India: A Review
}

\author{
S. P. Singh ${ }^{1 *}$, R. K. Naresh ${ }^{2}$, Yogesh Kumar ${ }^{1}$ and Robin Kumer ${ }^{3}$ \\ ${ }^{1}$ Department of Soil Science \& Agricultural Chemistry, Sardar Vallabhbhai Patel University \\ of Agriculture \& Technology, Meerut, (UP), India \\ ${ }^{2}$ Department of Agronomy, Sardar Vallabhbhai Patel University of Agriculture \& Technology, \\ Meerut, (UP), India \\ ${ }^{3}$ Department of Soil Science \& Agricultural Chemistry, Achrya Narendra Dev University of \\ Agriculture \& Technology, Kumar Gang, Ayodhya, (UP), India \\ *Corresponding author
}

Keywords

Soil organic carbon, SOC storage, Labile SOM dynamics, Aggregate stability

Article Info

Accepted:

10 July 2020

Available Online:

10 August 2020

\begin{abstract}
A B S T R A C T
Soil tillage can affect the stability and formation of soil aggregates by disrupting soil structure. Frequent tillage deteriorates soil structure and weakens soil aggregates, causing them to be susceptible to decay. Different types of tillage systems affect soil physical properties and organic matter content, in turn influencing the formation of aggregates. Retention of carbon (C) in arable soils has been considered as a potential mechanism to mitigate soil degradation and to sustain crop productivity. Soil organic carbon plays the crucial role in maintaining soil quality. The impact and rate of SOC sequestration in $\mathrm{CA}$ and conventional agriculture is still in investigation in this environment. Soil organic carbon buildup was affected significantly by tillage and residue level in upper depth of 0$20 \mathrm{~cm}$ but not in lower depth of 20-40 cm. Higher SOC content of $19.44 \mathrm{~g} \mathrm{~kg}^{-1}$ of soil was found in zero tilled residue retained plots followed by $18.53 \mathrm{~g} \mathrm{~kg}^{-1}$ in permanently raised bed with residue retained plots. Whereas, the lowest level of SOC content of $15.86 \mathrm{~g} \mathrm{~kg}^{-1}$ of soil were found in puddled transplanted rice followed by wheat planted under conventionally tilled plots. Zero tilled residue retained plots sequestrated $0.91 \mathrm{~g} \mathrm{~kg}^{-1} \mathrm{yr}^{-1}$ SOC which was $22.63 \%$ higher over the conventionally tilled residue removed plots. Therefore, CA in rice-wheat system can help directly in building-up of soil organic carbon and improve the fertility status of soil.
\end{abstract}

\section{Introduction}

Rice and wheat cropping system is very intensive and more exhaustive (Sharma and Behera 2011). Production and productivity of the system is very low (Regmi et al., 2003).
Declining or stagnant yield and impact on environment are major well known problems of cropping system (Khanal et al., 2012). Soil organic carbon is the fraction of organic matter; the decomposed plant and animal materials including microbial population. It is 
directly associated with nutrient availability, soil physical properties, and biological soil health and buffer actions over various toxic substances. Soil carbon level determined to the abundance of nutrient and equilibrium of various nutrient elements (Bot and Benites, 2005). With the increase in the concentration of soil organic carbon, yield of the crop is increased directly especially in sandy loam soil (Rattan and Datta, 2011). The major cause of yield decline in this system is nutrient imbalance, which is associated with soil organic matter, declining over time where intensive cropping has been experienced (Ladha et al., 2000). The equilibrium level of SOC in the soil is the function of climate, soil and nature of vegetation (Rattan and Datta, 2011). The carbon content was decreased up to by $15 \%$ per unit increase in $\mathrm{pH}$, increase by $1 \%$ per percent increase in clay content and decreased up to by $0.3 \%$ per percent increase in slope (Bronson et al., 1997).

Physical fractionation is widely used to study the storage and turnover of soil organic matter (SOM), because it incorporates three levels of analysis: SOM structural and functional complexity, and the linkage to functioning (Christensen, 2001; Wang et al., 2015). Soil aggregates, which are the secondary organomineral complexes of soil, are important for the physical protection of SOM. Thus, changes in soil aggregates may be used to characterize the impacts of management strategies on soil quality, including soil porosity, aeration, water retention, and erodibility (Christensen, 2001). Organic carbon (OC) stored in macro-aggregates has a stronger response to land-use change than that of SOC, and may be used as an important diagnostic indicator for the potential changes (Denef et al., 2007). To some extent, the protection of macroaggregates is considered to be fundamental for sustaining high SOC storage, and has been used in many ecological models (Wiesmeier et al., 2012; Gardenas et al., 2011).
Adoption of CA in rice-wheat system can be a logical and environment-friendly option to sustain or improve the productivity and economic viability of rice-wheat cropping system (Hobbs et al., 2008). Moreover, it can substantially improve soil properties through non-disturbance for a sufficiently longer period, and with retention of crop residue, physically protect the surface soil resulting in lesser run-off and higher water intake into the soil profile. In agro-ecosystems, soil aggregation formation is considered an important process in soil organic carbon (SOC) stabilization by hindering decomposition of SOC and its interactions with mineral particles (Gunina and Kuzyakov, 2014). Generally, a more rapid loss of SOC may occur from macro-aggregates than from micro-aggregates (Eynard et al., 2005). The SOC change under agricultural management may owe to the aggregate stability index (Nascente et al., 2015). Thus, soil aggregated fractionation has been widely applied to evaluate the SOC stability under contrasting tillage systems. The review study assessed that the adoption of $\mathrm{CA}$ in rice-wheat system for a few uninterrupted years can substantially improves the organic carbon carbon status, and reduce the sub-surface compaction and the modified soil environment may promote rice-wheat system productivity in directseeded/ unpuddled transplanted rice and notill wheat system, in comparison to a conventional system, where rice was puddletransplanted followed by conventionally tilled wheat.

\section{Annual Change in Soil Organic Carbon (g} $\mathrm{kg}^{-1} \mathrm{yr}^{-1}$ Soil)

Paudel et al., (2014) reported that ZTRZTW+RR had higher increase in soil carbon (0.91 $\mathrm{g} \mathrm{kg}^{-1} \mathrm{yr}^{-1}$ soil) followed by BPRBPW+RR (0.73 $\mathrm{g} \mathrm{kg}^{-1} \mathrm{yr}^{-1}$ soil) on upper depth $0-20 \mathrm{~cm}$. Carbon content was decreased in TPR-CTW for both depths. However, the 
mean soil organic carbon content at the upper 0 -20 $\mathrm{cm}$ depth was $17.25 \mathrm{~g} \mathrm{~kg}^{-1}$ soil before rice season and $17.58 \mathrm{~g} \mathrm{~kg}^{-1}$ soil after wheat season. The soil organic carbon at upper 0-20 $\mathrm{cm}$ depth was significantly influenced by conventional and conservation agricultural practices. Highest soil organic carbon change (122.63\%) was found in ZTR-ZTW + RR plots followed by BPR-BPW + RR plots (111.61\%). The use of ZTR-ZTW + RR and BPR-BPW+RR for five crop cycle increased soil organic carbon by $22.63 \%$ and $11.61 \%$ more than that of TPR-ZTW respectively. The percentage increment was smaller (22\% more than CT) than findings (64.6\% more than CT) of Calegari et al., (2008). Higher soil organic carbon content in residue retention could be attributed to more annual nutrient recycling in respective treatments and decreased intensity of mineralization (Kaisi and yin, 2005).

Chen et al., (2016) reported that the SOC concentration decreased with soil depth. In both $0-10$ and $10-20 \mathrm{~cm}$, the SOC concentration in the RP treatment was significantly greater than that in the other four treatments, yet no significant differences were found among the other four. In $20-30 \mathrm{~cm}$, there were in general no significant differences among all the rotation systems.

Zhao et al., (2018) reported that the SOC content of each aggregate class in the 0-20 $\mathrm{cm}$ layer was significantly higher than that in the $20-40 \mathrm{~cm}$ layer. Increases in the SOC content of aggregate fractions were highest in MRWR, followed by MR, and finally WR. Crop-derived organic particles or colloids can combine with mineral matter, binding microaggregates into macro-aggregates. Zhang et al., (2020) also found that that the silt + clay (SC) fractions $\quad(<0.053 \mathrm{~mm})$ were predominant, accounting for $32-56 \%$ of the mass at the $0-20 \mathrm{~cm}$ depth, and accounting for $41-55 \%$ of the mass at the $20-40 \mathrm{~cm}$ depth (Fig.1a). Additionally, long-term no-tillage management and straw-returning at different application rates increased the mass of large soil macro-aggregates (LMA), the LMA- and macro-aggregate- associated OC content, but decreased the SC-associated OC content. Mineral $\mathrm{N}$ and $\mathrm{P}$ fertilizers had a minor effect on the stabilization of soil aggregates. Moreover, SC fractions $(<0.053 \mathrm{~mm})$ were predominant, accounting for $32-56 \%$ of the mass of the $0-20 \mathrm{~cm}$ layer (Fig.1b). LMAs were the smallest fractions, accounting for 4$12 \%$ of the mass of the bulk soil at $0-20-\mathrm{cm}$ depth. The mass of LMAs was not significantly affected by the tillage method, mineral fertilizer, and straw (Fig. 1b). However, no-tillage increased LMA mass by $55 \%$ at $0-20 \mathrm{~cm}$ depth, compared with conventional tillage, (Fig.1b).

\section{Distribution of soil aggregates with different sizes}

Jiang et al., (2011) reported that the aggregate-associated SOC concentration in different soil layers was influenced by tillage systems. In the 0.00-0.05 $\mathrm{m}$ layer, SOC concentration in macro-aggregates showed the order of $\mathrm{NT}+\mathrm{S}>\mathrm{MP}+\mathrm{S}=\mathrm{NT}-\mathrm{S}>\mathrm{MP}-\mathrm{S}$, whereas the NT system was superior to the MP system. However, the NT system significantly reduced the SOC concentration in the $2.00-0.25 \mathrm{~mm}$ fraction in the $0.05-0.20$ $\mathrm{m}$ layer. A similar trend was observed in the $0.25-0.053 \mathrm{~mm}$ fraction in the $0.20-0.30 \mathrm{~m}$ layer. Across all the soil layers, there was no difference in the $<0.053 \mathrm{~mm}$ fraction between NT-S and MP-S, as well as between NT+S and $\mathrm{MP}+\mathrm{S}$, indicating that the NT system did not affect the SOC concentration in the silt + clay fraction. In average across the soil layers, the SOC concentration in the macro-aggregate was increased by $13.5 \%$ in $\mathrm{MP}+\mathrm{S}, 4.4 \%$ in $\mathrm{NT}-\mathrm{S}$ and $19.3 \%$ in $\mathrm{NT}+\mathrm{S}$, and those in the micro-aggregate $<0.25 \mathrm{~mm}$ were increased by $6.1 \%$ in $\mathrm{MP}+\mathrm{S}$ and $7.0 \%$ in $\mathrm{NT}+\mathrm{S}$ compared to MP-S. For all the soil layers, the 
SOC concentration in all the aggregate size classes was increased with straw incorporation, by 20.0, 3.8 and $5.7 \%$ under the MP system, and 20.2, 6.3 and $8.8 \%$ under the NT system.

Dou et al., (2016) also found that an application of organic and inorganic fertilizers increased the weight distribution of $<53 \mu \mathrm{m}$ size fraction compared with CK. In general, the aggregate distribution was dominated by macro-aggregates $\quad(2000-250 \mu \mathrm{m} ; \quad 48.31-$ $64.10 \%$ ) across all the fertilizer treatments. Long-term MNPK fertilizer strongly increased the SOC storage by an average of $466.0 \mathrm{~g} \mathrm{C} \mathrm{m}^{2}$ in all aggregates. The SNPK fertilizer increased SOC by an average of $191.1 \mathrm{~g} \mathrm{C} \mathrm{m}^{2}$ in macro-aggregates $(>250 \mu$ $\mathrm{m})$ but decreased it by an average of $131.4 \mathrm{~g}$ $\mathrm{C} \mathrm{m}^{2}$ in micro-aggregates $(250-53 \mu \mathrm{m})$ compared with $\mathrm{CK}$. Besides, the SOC storage showed a decrease in $250-53 \mu \mathrm{m}$ aggregates compared with other aggregate sizes in the fertilized soils except for MNPK treatment. Generally, the SOC storage in macroaggregates $(>250 \mu \mathrm{m})$ was greater than in micro-aggregates $(<250 \mu \mathrm{m})$ across the fertilizer treatments.

Ou et al., (2016) revealed that tillage systems obviously affected the distribution of soil aggregates with different sizes. The proportion of the $>2 \mathrm{~mm}$ aggregate fraction in $\mathrm{NT}+\mathrm{S}$ was $7.1 \%$ higher than that in NT-S in the $0.00-0.05 \mathrm{~m}$ layer. There was no significant difference in the total amount of all the aggregate fractions between $\mathrm{NT}+\mathrm{S}$ and NT-S in both the $0.05-0.20$ and $0.20-0.30 \mathrm{~m}$ layers. NT+S and NT-S showed higher proportions of $>2 \mathrm{~mm}$ aggregate and lower proportions of $<0.053 \mathrm{~mm}$ aggregate compared to the MP system for the 0.00-0.20 $\mathrm{m}$ layer. The proportion of $>0.25 \mathrm{~mm}$ macroaggregate was significantly higher in $\mathrm{MP}+\mathrm{S}$ than in MP-S in most cases, but the proportion of $<0.053 \mathrm{~mm}$ aggregate was
11.5-20.5 \% lower in MP+S than in MP-S for all the soil layers. Souza Nunes et al., (2011) also reported that the NT system resulted in stratification of SOC, while the MP system resulted in a more homogeneous distribution in the $0.00-0.20 \mathrm{~m}$ layer.

Dhaliwal et al., (2018) revealed that the mean SOC concentration decreased with the size of the dry stable aggregates (DSA) and water stable aggregates (WSA). In DSA, the mean SOC concentration was 58.06 and $24.2 \%$ higher in large and small macro-aggregates than in micro-aggregates, respectively; in WSA it was 295.6 and $226.08 \%$ higher in large and small macro-aggregates than in micro-aggregates respectively in surface soil layer. The mean SOC concentration in surface soil was higher in DSA $(0.79 \%)$ and WSA $(0.63 \%)$ as compared to bulk soil $(0.52 \%)$. Prasad et al., (2019) also found that tillage significantly reduced the proportion of macroaggregate fractions (> $2.00 \mathrm{~mm}$ ) and thus aggregate stability was reduced by $35 \%$ compared with (ridge with no tillage) RNT, indicating that tillage practices led to soil structural change for this subtropical soil. The highest SOC was in the $1.00-0.25 \mathrm{~mm}$ fraction (35.7 and $30.4 \mathrm{mgkg}^{-1}$ for RNT and $\mathrm{CT}$ ), while the lowest SOC was in microaggregate $(<0.025 \mathrm{~mm})$ and silt + clay $(<0.053 \mathrm{~mm})$ fractions $\left(19.5\right.$ and $15.7 \mathrm{mg} \mathrm{kg}^{-1}$ for RNT and CT, respectively).

Zheng et al., (2013) revealed that NT and RT treatments significantly increased the proportion of macro-aggregate fractions ( $>2000 \mu \mathrm{m}$ and $250-2000 \mu \mathrm{m})$ compared with the MP-R and MP $+\mathrm{R}$ treatments. For the 0 $5 \mathrm{~cm}$ depth, the total amount of macroaggregate fractions $(>250 \mu \mathrm{m})$ was increased by $65 \%$ in NT and $32 \%$ in RT relative to the $\mathrm{MP}+\mathrm{R}$. Averaged across all depths, the macro- aggregate fraction followed the order of $\mathrm{NT}(0.39)>\mathrm{RT}(0.30)>\mathrm{MP}+\mathrm{R}$ $(0.25)=\mathrm{MP}-\mathrm{R} \quad(0.24)$. Accordingly, the 
proportion of micro-aggregate fraction (53$250 \mu \mathrm{m})$ was increased with the intensity of soil disturbance. In the $0-5$ and $5-10 \mathrm{~cm}$ depths, NT and RT had significantly higher total soil $\mathrm{C}$ concentration than that of $\mathrm{MP}-\mathrm{Rand} \mathrm{MP}+\mathrm{R}$ in all aggregate size fractions. However, in the $10-20 \mathrm{~cm}$ depth, conservation tillage system reduced total $\mathrm{C}$ concentration in the macro-aggregate fraction $(>250 \mu \mathrm{m})$ but not in the micro-aggregate and silt plus clay fractions. The greatest change in aggregate $\mathrm{C}$ appeared in the large macroaggregate fractions where aggregateassociated $\mathrm{C}$ concentration decreased with depth. In the $0-5 \mathrm{~cm}$ depth, the $>2000 \mu \mathrm{m}$ fraction had the largest $\mathrm{C}$ concentration under NT, whereas the $<53 \mu \mathrm{m}$ fraction had the lowest $\mathrm{C}$ concentration under the MP-R treatment. Similar trend was also observed in the $>2000 \mu \mathrm{m}$ and $25-2000 \mu \mathrm{m}$ fractions $(23$ vs.24 $\mathrm{g} \mathrm{C} \mathrm{kg}^{-1}$ aggregates) in the $5-10 \mathrm{~cm}$ depth. The large macro-aggregate $(>2000 \mu \mathrm{m})$ had relatively lower $\mathrm{C}$ concentration than that in the $>250-2000 \mu \mathrm{m}$ fraction in the $10-20 \mathrm{~cm}$ depth. Averaged across soil depths, all aggregate size fractions had 6-9\%higher total soil $\mathrm{C}$ concentration in $\mathrm{NT}$ and $\mathrm{RT}$ than in $\mathrm{MP}-\mathrm{R}$ and $\mathrm{MP}+\mathrm{R}$, except for the 53-250 $\mu \mathrm{m}$ fraction. Again mould-board plough showed slightly higher soil $\mathrm{C}$ concentration than the conservation tillage systems in the $53-250 \mu \mathrm{m}$ fraction.

\section{Fractions of soil organic carbon}

Parihar et al., (2018) reported that plots under ZT and PB had larger C pools and a larger proportion of labile $\mathrm{C}$ to total SOC than for the CT plots at 0-5-, 5-15- and 15-30-cm soil depths. Among the maize-based crop rotations, the plots with $\mathrm{MWMb}$ and MCS systems resulted in greater accumulation of labile-C pools and proportion of labile-C to total SOC at 0-5-, 5-15- and 15-30-cm soil depths. However, the proportion of non-labile-C to total SOC was larger in the
MMS and MMuMb system plots at 0-5-, 515- and 15-30-cm soil depths. Mondal et al., (2019) revealed that TOC of soil differed significantly among the treatments in the 0-5 $\mathrm{cm}$ layer. The highest value of TOC was recorded in NT-NT3 $(9.58 \mathrm{~g} / \mathrm{kg})$, which was significantly higher $\left(38-46 \%\right.$, than $\mathrm{NT}^{-\mathrm{NT}_{1}}$ $(6.54 \mathrm{~g} / \mathrm{kg})$ and CT-CT $(6.92 \mathrm{~g} / \mathrm{kg})$, but was comparable to $\mathrm{NT}^{-\mathrm{NT}_{2}}(8.78 \mathrm{~g} / \mathrm{kg})$ and CTNT $(8.70 \mathrm{~g} / \mathrm{kg})$. In the below layer $(5-15 \mathrm{~cm})$, variation in TOC content reduced (5.23-5.86 $\mathrm{g} / \mathrm{kg}$ ), and both NT-NT 1 and NT-NT 3 had significantly higher (11-12\%, TOC content than the CT-CT. Mean values of TOC was higher by $34 \%$ in NT. This highlights the favorable condition of soil organic carbon accumulation through no-tillage practice. Addition of crop residue and incorporation of legume in crop rotation in NT-NT $\mathrm{N}_{3}$ treatment could be the possible cause of higher TOC content in the soil. Residues get slowly decomposed and the resultant organic matter is added to the soil which helps in aggregate formation, water retention and improves overall soil physical health. In subsurface layers, TOC content was almost comparable between CT and NT, which implies that the role of tillage and crop residue is restricted to the surface layer (Meurer et al., 2017).

Johnson et al., (2013) also found that the intensive tillage at the Chisel field showed $<20 \%$ of the soil covered for all stover treatments, including full return, where all residues were returned; whereas, $\mathrm{NT}_{2005}$ and $\mathrm{NT}_{1995}$ had at least $45 \%$ of the soil covered even in low return. In $\mathrm{NT}_{2005}$, significant increases in aggregates $<1 \mathrm{~mm}$ and significant decreases in aggregates 5-9 $\mathrm{mm}$ were measured in low return compared to full return [Fig. 2]. Low Return had $15 \%$ and $60 \%$ more aggregates in the $0-0.5$ and $0.5-1 \mathrm{~mm}$ classes, respectively, compared to full return, but full return had $14 \%$ more 5-9 mm aggregates compared to low return, with moderate return intermediate. In Chisel and 
$\mathrm{NT}_{1995}$, although means of aggregate distribution displayed a similar trend to the $\mathrm{NT}_{2005}$, no statistically significant increase in the frequency of aggregates $<1 \mathrm{~mm}$ was detected [Fig. 2].

Ratnayake et al., (2019) reported that AHG showed the highest TOC, although it was not significantly different from that of $\mathrm{A}-\mathrm{OF}$ in both soil layers (Fig. 3a). On the other hand, the lowest TOC was recorded in A-OFS in both layers. However, it was not significantly different from that in USR. The highest MBC was observed in $\mathrm{A}-\mathrm{OF}$ at both depths, although it was not significantly different from that of HG (Fig. 3b). The lowest MBC, at both depths, was found in A-OFS, and the difference was significant. Water-soluble C (WSC) content was relatively high in home gardens ( $\mathrm{HG}, \mathrm{AHG}$ ) and $\mathrm{A}-\mathrm{O} / \mathrm{IF}$, while it had lowest mean values in A-OFS and USR (Fig. 3c). Permanganate oxidizable $\mathrm{C}$ (POC) was the highest in $\mathrm{A}-\mathrm{O} / \mathrm{IF}$ at both depth interval sand the difference was statistically significant when compared with other land uses types (Fig. 3d).

In the 0.00-0.05 m layer, SOC concentration in macro-aggregates showed the order of $\mathrm{NT}+\mathrm{S}>\mathrm{MP}+\mathrm{S}=\mathrm{NT}-\mathrm{S}>\mathrm{MP}-\mathrm{S}$, whereas the NT system was superior to the MP system. However, the NT system significantly reduced the SOC concentration in the 2.00$0.25 \mathrm{~mm}$ fraction in the $0.05-0.20 \mathrm{~m}$ layer. A similar trend was observed in the 0.25-0.053 $\mathrm{mm}$ fraction in the $0.20-0.30 \mathrm{~m}$ layer. Across all the soil layers, there was no difference in the $<0.053 \mathrm{~mm}$ fraction between NT-S and $\mathrm{MP}-\mathrm{S}$, as well as between NT $+\mathrm{S}$ and MP + $\mathrm{S}$, indicating that the NT system did not affect the SOC concentration in the silt + clay fraction. In average across the soil layers, the SOC concentration in the macro-aggregate was increased by $13.5 \%$ in MP $+\mathrm{S}, 4.4 \%$ in NT-S and $19.3 \%$ in NT $+\mathrm{S}$, and those in the micro-aggregate $(<0.25 \mathrm{~mm})$ were increased by $6.1 \%$ in $\mathrm{MP}+\mathrm{S}$ and $7.0 \%$ in $\mathrm{NT}+\mathrm{S}$ compared to MP-S. For all the soil layers, the SOC concentration in all the aggregate size classes was increased with straw incorporation, by 20.0, 3.8 and $5.7 \%$ under the MP system, and 20.2, 6.3 and $8.8 \%$ under the NT system. The higher proportion of $>2$ $\mathrm{mm}$ aggregates and lower proportion of $<0.053 \mathrm{~mm}$ aggregates under NT systems might be the result of the higher soil hydrophobicity, low intensity of wetting and drying cycles, higher soil $\mathrm{C}$ concentration or the physical and chemical characteristics of large macro-aggregates making them more resistant to breaking up (Vogelmann et al., 2013). Six et al., (1998) concluded that the concentration of free LF $\mathrm{C}$ was not affected by tillage, but was on average $45 \%$ less in the cultivated systems than NV. Proportions of crop-derived $\mathrm{C}$ in macro-aggregates were similar in NT and CT, but were three times greater in micro-aggregates from NT than micro-aggregates from CT. Moreover, the rate of macro-aggregates in CT compared with NT leads to a slower rate of micro-aggregate formation within macro-aggregates and less stabilization of new SOM in free microaggregates under CT [Fig. 4].

Zheng et al., (2018) also found that The SOC content for different treatments decreased with soil depth with significantly higher content in the topsoil than in the sub-layer. At the $0-10 \mathrm{~cm}$ depth, the mean SOC varied with treatment, with the conservation tillage (ST and NT) significantly higher than conventional tillage (CT). At $10-30 \mathrm{~cm}$, especially, the ST treatment was significantly higher. At $20-30 \mathrm{~cm}$, the mean SOC from greatest to smallest was ordered ST> MP> CT> NT, with ST significantly higher than other treatments. Zhang et al., (2020) observed that the treatment of $\mathrm{CT}_{1}-\mathrm{N}_{1}-\mathrm{P}_{1}-\mathrm{Straw}_{1}$ significantly increased the OC content of the bulk soil compared $\mathrm{CT}_{1}-\mathrm{N}_{2}-\mathrm{P}_{2}-\mathrm{Straw}_{2}$ and other treatments at the 
0-20 $\mathrm{cm}$ depth. When the treatment without straw $\left(\mathrm{CT}_{1}-\mathrm{N}_{0}-\mathrm{P}_{0}-\mathrm{Straw}_{0}, \mathrm{CT}_{2}-\mathrm{N}_{1}-\mathrm{P}_{2}-\mathrm{Straw} 0\right.$, and $\mathrm{NT}-\mathrm{N}_{2}-\mathrm{P}_{1}-\mathrm{Straw}_{0}$ ), soil aggregateassociated OC was highest in the SC fractions than other three aggregate fractions, ranging from $30-50 \%$ of bulk soil OC at $0-20 \mathrm{~cm}$ depth. Whether conventional tillage or no-tillage method, the treatment with straw returning increased the aggregate-associated OC content of LMAs, MAs, and MIs. This result showed that straw changed the distribution of $\mathrm{OC}$ in the different size aggregates.

Gu et al., (2016) reported that the adoption of GT and ST increased LOC contents in the 0$100 \mathrm{~cm}$ soil profile by $0.102 \mathrm{~g} \mathrm{~kg}^{-1}$ and 0.136 $\mathrm{g} \mathrm{kg}^{-1}$ respectively, compared to $\mathrm{CK}$, and there was a $70-80 \%$ increase in the $0-40 \mathrm{~cm}$ layer (Fig.5). The higher values of LOC in ST and GT can possibly be attributed to the inputs from organic materials and root residues, as well as decreased losses with surface runoff as a result of mulching (Gale et al., 2000; Wander and Yang, 2000). The DOC concentration is considerably lower than those of other labile $\mathrm{C}$ fractions, generally not more than $200 \mathrm{mg} \mathrm{kg}^{-1}$, but it is the most mobile fraction of SOC. It controls the turnover of nutrient and organic matter by affecting the development of microbial populations. In this experiment, ST and GT treatments significantly increased soil DOC concentrations at depths of $0-40 \mathrm{~cm}$, by $28.56 \%$ and $23.33 \%$ respectively, (Fig.5) compared to $\mathrm{CK}$, but there was no difference between ST and GT treatments at each layer of the soil profile. The increase in DOC with ST may be due to the soluble decomposed organic materials of the straw, while the increase in DOC with GT could possibly be attributed to an increase in organic acids and water-soluble carbohydrates from rhizodeposition and root exudates. In addition, a decrease in surface runoff under GT and ST was an important reason for the increased DOC, as DOC may be lost with runoff. Compared with $\mathrm{CK}$, the DOC in GT and ST was favorably leached, deposited and absorbed into the subsoil layer, resulting in higher concentrations of DOC at depths of 20$40 \mathrm{~cm}$ (Fig.5). This was probably because of low soil bulk density in ST, and in GT lower $\mathrm{pH}$ would have increased DOC adsorption by soil (Jardine et al., 1989).

\section{SOC storage in different aggregate size fractions}

Ou et al., (2016) reported that as compared to MP-S, the SOC stock in the $>2 \mathrm{~mm}$ aggregate fraction increased and that in the $<0.053 \mathrm{~mm}$ fraction declined in $\mathrm{MP}+\mathrm{S}, \mathrm{NT}-\mathrm{Sand} \mathrm{NT}+\mathrm{S}$ in the 0.00-0.05 and 0.05-0.20 m layers. Within the $0.00-0.20 \mathrm{~m}$ layer, the SOC stock in the $>2 \mathrm{~mm}$ aggregate fraction was increased by $28.1,56.1$ and $88.4 \%$, and that in the $<0.053$ $\mathrm{mm}$ aggregate fraction decreased by 17.7 , 30.3 and $34.2 \%$ in $\mathrm{MP}+\mathrm{S}, \mathrm{NT}-\mathrm{S}$ and $\mathrm{NT}+\mathrm{S}$ than in MP-S. The SOC stock in the 2.00-0.25 $\mathrm{mm}$ aggregate fraction did not differ among the $\mathrm{MP}+\mathrm{S}, \mathrm{NT}-\mathrm{S}$ and $\mathrm{NT}+\mathrm{S}$ treatments, but was significantly increased compared to the 0.00-0.05 m layer for MP-S treatment. There was a significant increase in SOC stock of macro-aggregate in $\mathrm{MP}+\mathrm{S}$ than in $\mathrm{MP}-\mathrm{S}$ as well as in NT+S than in NT-S in the 0.05-0.20 and $0.20-0.30 \mathrm{~m}$ layers. Maximum increase in TOC stock under $\mathrm{S}_{3}$ might be due to the highest addition of crop residues coupled with conservation tillage (Das et al., 2013). Ploughing of soil causes breakage of macroaggregates into micro-aggregate and silt and clay size particles inside soil (Bronick and Lal, 2005) exposing protected organic carbon inside macro-aggregate for oxidation. The principal cause of higher enrichment of SOC on top depth was more crop residue addition on top soil in comparison to soil of lower depth. Along with this, the root growth is limited by lesser nutrient and microbial activity in lower depth resulting in lower total 
addition of crop residues in lower depth (Tiwari et al., 1995).

$\mathrm{Xu}$ et al., (2013) observed that the SOC stocks in the 0-80 cm layer under NT was as high as $129.32 \mathrm{Mg} \mathrm{C} \mathrm{ha}{ }^{-1}$, significantly higher than those under PT and RT. The order of SOC stocks in the $0-80 \mathrm{~cm}$ soil layer was $\mathrm{NT}>\mathrm{PT}>\mathrm{RT}$, and the same order was observed for SCB; however, in the $0-20 \mathrm{~cm}$ soil layer, the RT treatment had a higher SOC stock than the PT treatment. Mangalassery et al., (2014) also found that zero tilled soils contained significantly more soil organic matter (SOM) than tilled soils. Soil from the 0-10 cm layer contained more SOM than soils from the $10-20 \mathrm{~cm}$ layers in both zero tilled $(7.8$ and $7.4 \%$ at $0-10 \mathrm{~cm}$ and $10-20$ $\mathrm{cm}$, respectively) and tilled soils (6.6\% at 0 $10 \mathrm{~cm}$ and $6.2 \%$ at $10-20 \mathrm{~cm}$ ).

Meenakshi, (2016) revealed that under conventional tillage, the organic carbon content in the surface $0-15 \mathrm{~cm}$ soil depth was $0.44,0.51$ and $0.60 \%$ which was increased to $0.60,0.62$ and $0.70 \%$ under zero tillage practice in sandy loam, loam and clay loam soil. In all the three soils, the organic carbon decreased significantly with depth under both the tillage practices. Under conventional tillage, the amount of organic carbon observed in $0-15 \mathrm{~cm}$ found to decrease abruptly in $15-30 \mathrm{~cm}$ soil depth as compared to the decrease under zero tillage practice in all the soils. Long term ZT practice in wheat increased the organic carbon content significantly as compared to CT in different depths of all the soils. As expected, the higher amount of organic carbon was observed in relatively heavier textured soil viz., clay loam $>$ loam > sandy loam at both the depths. Moreover, under conventional tillage, the light fraction carbon, in the surface $0-15 \mathrm{~cm}$ soil depth was $0.29,0.49$ and $0.58 \mathrm{~g} \mathrm{~kg}^{-1}$ which increased to $0.43,0.62$ and $1.01 \mathrm{~g} \mathrm{~kg}^{-1}$ under zero tillage practice in sandy loam, loam and clay loam soil. The heavy fraction carbon in the surface $0-15 \mathrm{~cm}$ soil layer was $3.8,4.2$ and $4.9 \mathrm{~g} \mathrm{~kg}^{-1}$ which decreased to 2.0 , 2.2 and $2.6 \mathrm{~g} \mathrm{~kg}^{-1}$ in $15-30 \mathrm{~cm}$ soil layer in sandy loam, loam and clay loam, respectively. The heavy fraction carbon was highest in the surface layer in all the three soils and decreased with depth under both tillage treatments. The zero tillage resulted in an increase in heavy fraction carbon at both the depth. In the surface $0-15 \mathrm{~cm}$, it increased the heavy fraction carbon significantly from 3.8 to $4.9,4.2$ to 4.9 and 4.9 to $5.1 \mathrm{~g} \mathrm{~kg}^{-1}$ and in $15-30 \mathrm{~cm}$ soil depth from 2.0 to $2.9,2.2$ to 3.4 and 2.6 to $3.9 \mathrm{~g} \mathrm{~kg}^{-1}$ in sandy loam, loam and clay loam. Relatively higher amount of heavy fraction carbon was observed in heavier textured soil at both the depth.

Wang et al., (2018) reported that tillage system change influenced SOC content, NT, $\mathrm{ST}$, and BT showed higher values of SOC content and increased 8.34, 7.83, and $1.64 \mathrm{MgCha}^{-1}$, respectively, compared with CT. Among the 3 changed tillage systems, NT and ST showed a $12.5 \%$ and $11.6 \%$ increase in SOC content then BT, respectively. Tillage system change influenced SOC stratification ratio values, with higher value observed in $\mathrm{BT}$ and NT compared CT but ST. Therefore, in loess soil, changing tillage system can significantly improve SOC storage and change profile distribution. Kumar et al., (2019) revealed that the soil organic carbon (SOC) stock in bulk soil was 40.2-51.1\% higher in the 0.00-0.05 $\mathrm{m}$ layer and 11.3$17.0 \%$ lower in the $0.05-0.20 \mathrm{~m}$ layer in NT system no-tillage without straw (NT-S) and with straw $(\mathrm{NT}+\mathrm{S})$, compared to the MP system moldboard plow without straw (MP-S) and with straw $(\mathrm{MP}+\mathrm{S})$, respectively. Residue incorporation caused a significant increment of $15.65 \%$ in total water stable aggregates in surface soil $(0-15 \mathrm{~cm})$ and $7.53 \%$ in subsurface soil $(15-30 \mathrm{~cm})$. In surface soil, the maximum (19.2\%) and minimum (8.9\%) 
proportion of total aggregated carbon was retained with $>2 \mathrm{~mm}$ and $0.1-0.05 \mathrm{~mm}$ size fractions, respectively. At 0-7 cm depth, soil MBC was significantly higher under plowing tillage than rotary tillage, but EOC was just opposite. Rotary tillage had significantly higher soil TOC than plowing tillage at 7-14 cm depth. However, at 14-21 cm depth, TOC, DOC and MBC were significantly higher under plowing tillage than rotary tillage except for EOC. A considerable proportion of the total SOC was found to be captured by the macro-aggregates $(>2-0.25 \mathrm{~mm})$ under both surface $(67.1 \%)$ and sub-surface layers $(66.7 \%)$ leaving rest amount in microaggregates and "silt + clay" sized particles. $\mathrm{Gu}$ et al., (2016) observed that mulching practices did not alter the seasonal dynamic changes of LOC, but could increase its content, e.g., in March, ST and GT increased LOC by $167 \%$ and $122 \%$ respectively (Fig. 6).

\section{Soil aggregate stability}

Tillage system and crop rotation are essential factors in agricultural systems that influence soil fertility and the formation of soil aggregates (Saljnikov et al., 2013). The stability of soil aggregates defines soil structure and influences crop development. A good soil structure has a stable aggregate fraction that tolerates different wetting conditions in particular and provides continuity of pores in the soil matrix, which improves soil air and moisture exchange between the roots and soil environment. Soils under no-till can have greater soil strength due to stable soil aggregates and soil biodiversity that contribute to the enhancement of water and nutrients available to plants for growth and development (Stirzaker et al., 1996). Chen et al., (2009) also found that the portion of $0.25-2 \mathrm{~mm}$ aggregates, mean weight diameter (MWD) and geometric mean diameter (GMD) of aggregates from ST and NT treatments were larger than from CT at both 0-15- and 15-30cm soil depths.

Mondal et al., (2019) reported that in 0-7.5 $\mathrm{cm}$ layer under fast-wetting pre-treatment condition, soil macro-aggregate content was significantly higher in NT-NT 3 (56- $287 \%$ while CT-CT recorded the lowest content $(22.7 \%)$. Similar trend could be found in the following 7.5-15 cm layer, where the highest and the lowest amount of macro-aggregates were recorded in $\mathrm{NT}_{-} \mathrm{NT}_{3}(48.2 \%)$ and CTNT (19.9\%), respectively. In $15-30 \mathrm{~cm}$ soil layer, macro-aggregates content was higher in NT-NT 3 compared to CT-NT and CT-CT (50$68 \%$, but was at par with NT-NT 1 and NT$\mathrm{NT}_{2}$. Amount of soil micro-aggregates followed the reverse; both CT-NT and CT-CT recorded 24- $115 \%$ higher in microaggregates content compared to NT-NT 2 and $\mathrm{NT}-\mathrm{NT}_{3}$, but similar to NT-NT . Amount of stable macro-aggregates were nearly doubled with slow-wetting pre-treatment. NT-NT 2 recorded significantly higher content than CTCT and CT-NT (42 and 22\%, respectively, but it was at par with other treatments. Similar results were obtained in 7.5-15 cm layer. No significant difference was found at $15-30 \mathrm{~cm}$ layer. In slow-wetting, micro-aggregate contents were comparable among the treatments at all the layers. Greater macroaggregates ensured larger mean weight diameter (MWD) in NT-NT $3(0.59 \mathrm{~mm})$, followed by NT-NT $2(0.47 \mathrm{~mm})$, NT-NT1 $(0.41 \mathrm{~mm})$, CT-NT $(0.36 \mathrm{~mm})$ and CT-CT $(0.29 \mathrm{~mm})$ in $0-7.5 \mathrm{~cm}$ soil layer, when the fast-wetting pre-treatment was followed. In 7.5-15 cm layer, MWD was lower compared to the layer above, and NT-NT 3 could only have a significantly different (56-77\% higher, MWD compared to the rest of the treatments. In 15-30 cm layer, treatments were at par. When aggregates were slow-wetted, MWD improved and was 2-3 times higher than the corresponding fast-wetting MWD. Here, 
MWD of aggregates significantly higher in NT-NT 3 (44-195\% than all other treatments except NT-NT 2 . Similar results were obtained in other layers, and MWD in NT-NT 3 was higher compared to CT-NT and CT-CT treatments.

Fig.1a Soil organic carbon (OC) content $\left(\mathrm{g} \mathrm{kg}^{-1}\right.$ soil) in four aggregate size fractions $(>2,0.25-$ $2,0.053-0.25$, and $<0.053 \mathrm{~mm}$ ) in $0-20$ and $20-40 \mathrm{~cm}$

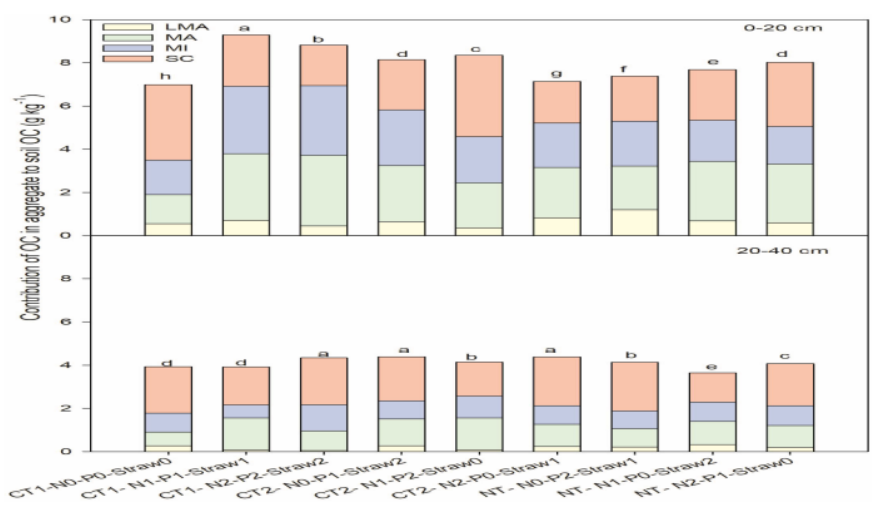

Fig.1b Mass distribution of four different size aggregates ( $>2,0.25-2,0.053-0.25$, and $<0.053$ $\mathrm{mm}$ ) under tillage and fertilization treatments from $0-20$ and $20-40 \mathrm{~cm}$

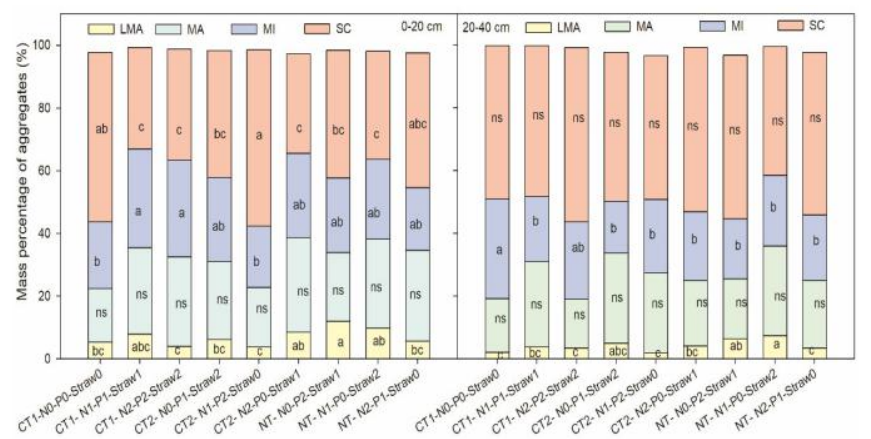

Fig.2 Dry aggregate size distribution as affected by Stover return rates

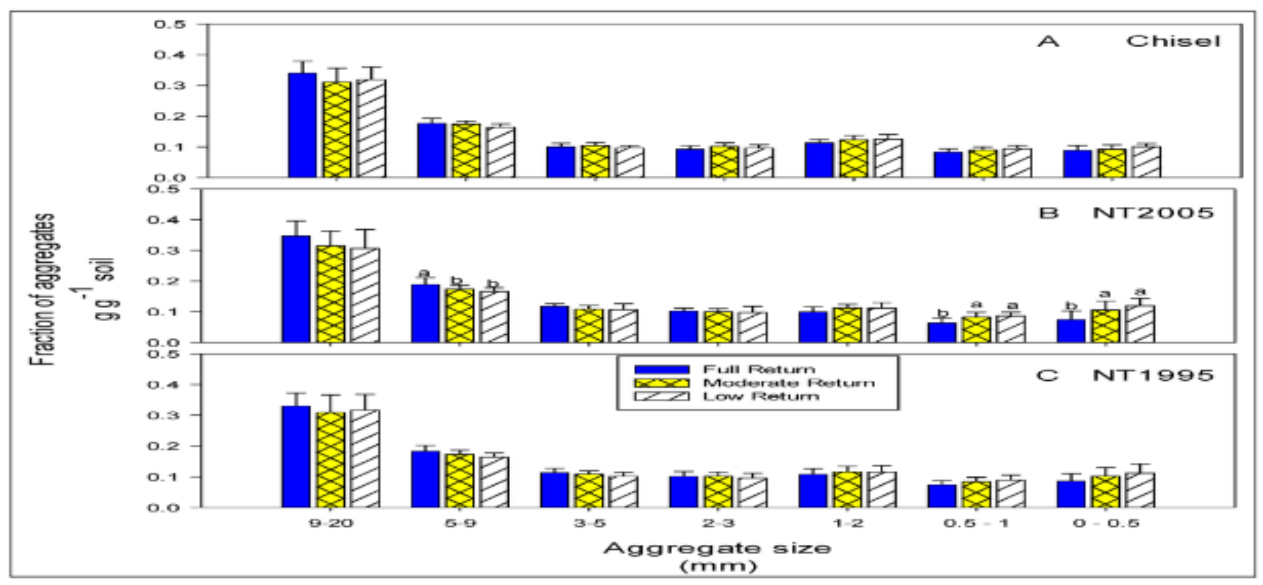


Fig.3 C fractions levels at selected land uses: total organic C (TOC) variation in different land uses (a), microbial biomass carbon (MBC) variation in different land uses (b), water soluble C

(WSC) variation in different land uses (c), $\mathrm{KMnO} 4$ oxidizable carbon (POC) variation in different land uses.
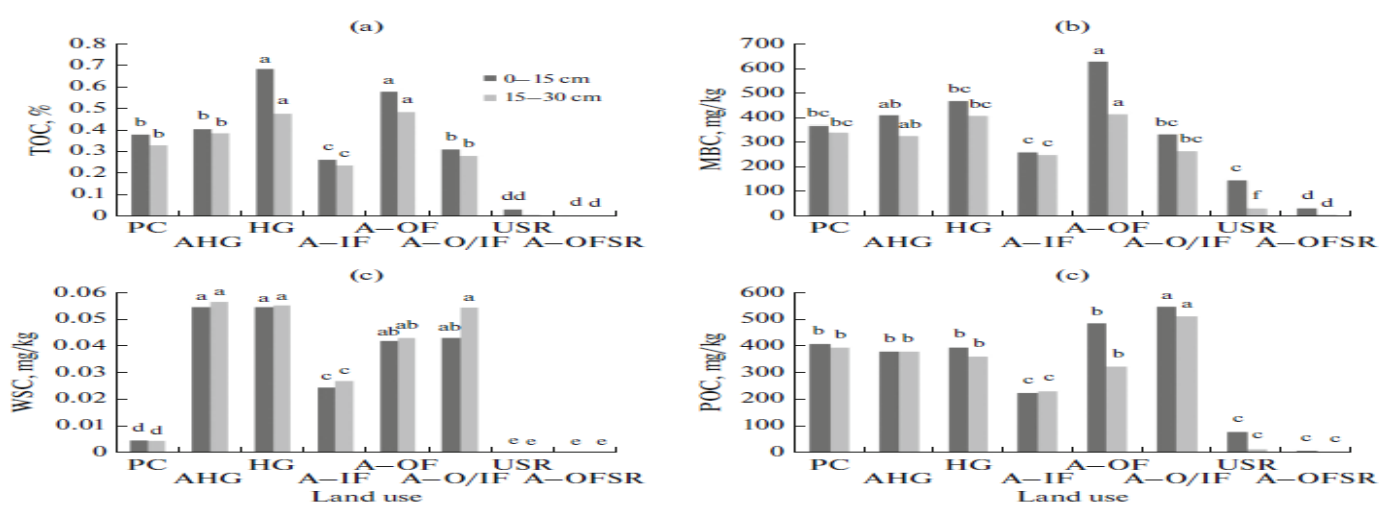

Fig.4 Aggregate and Soil Organic Matter Dynamics under Conventional and No-Tillage Systems

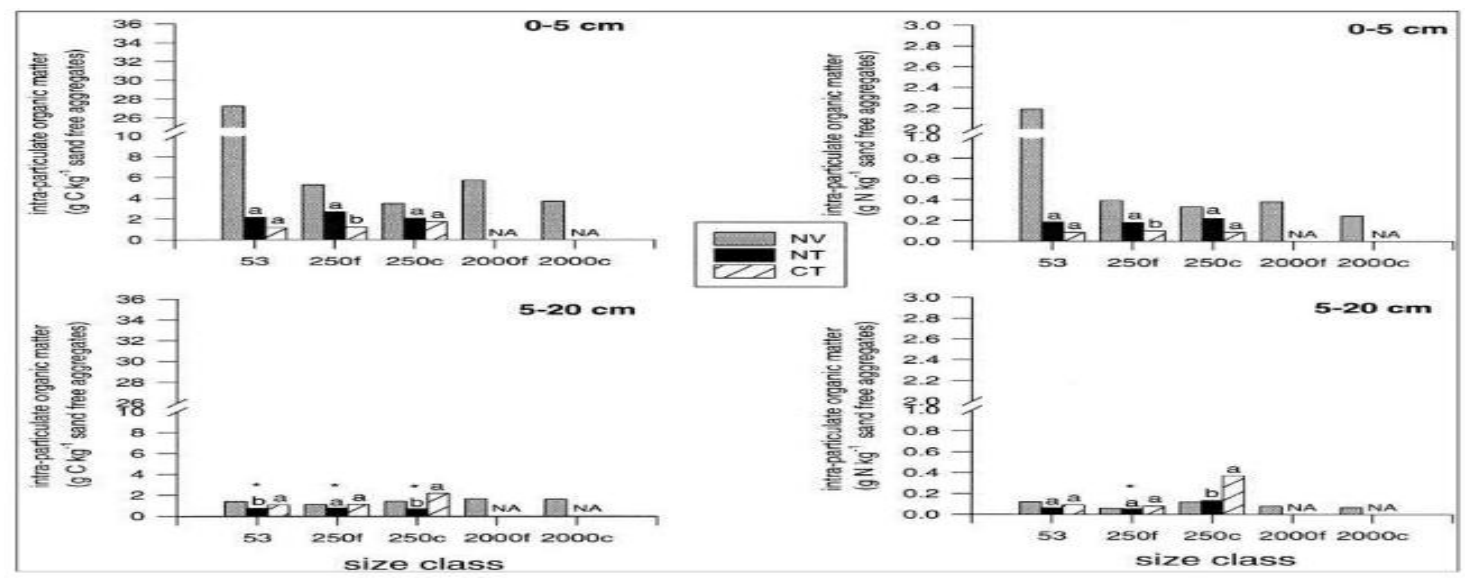

Fig.5 Content of Carbon fractions at different depths.
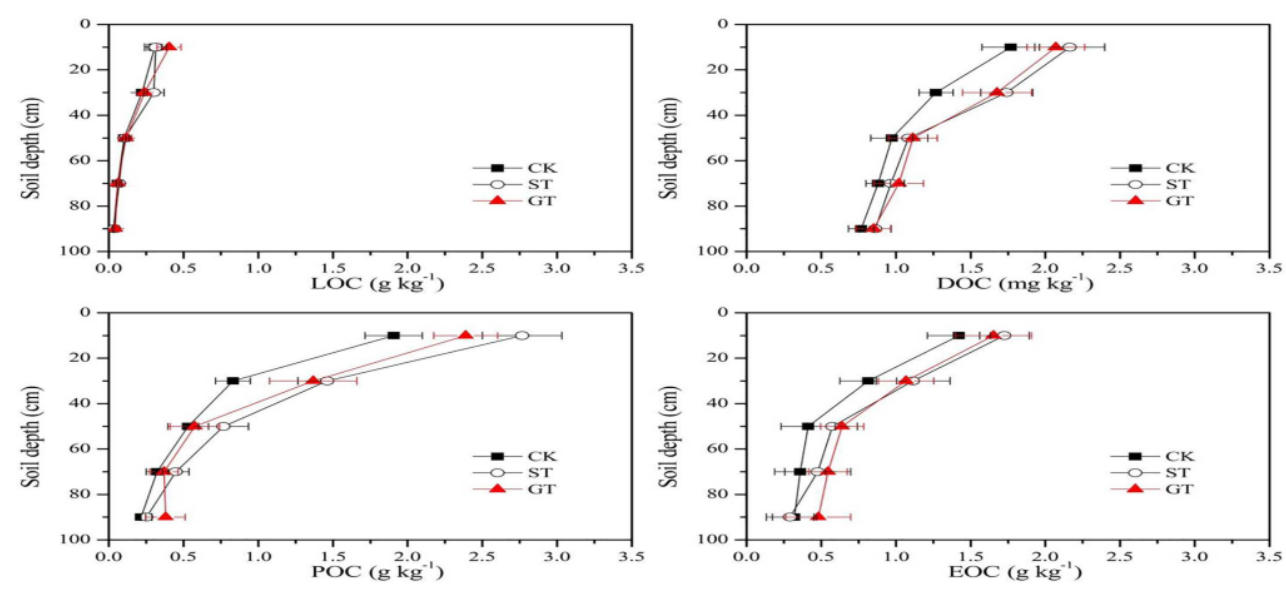
Fig.6 Dynamic changes of carbon fractions
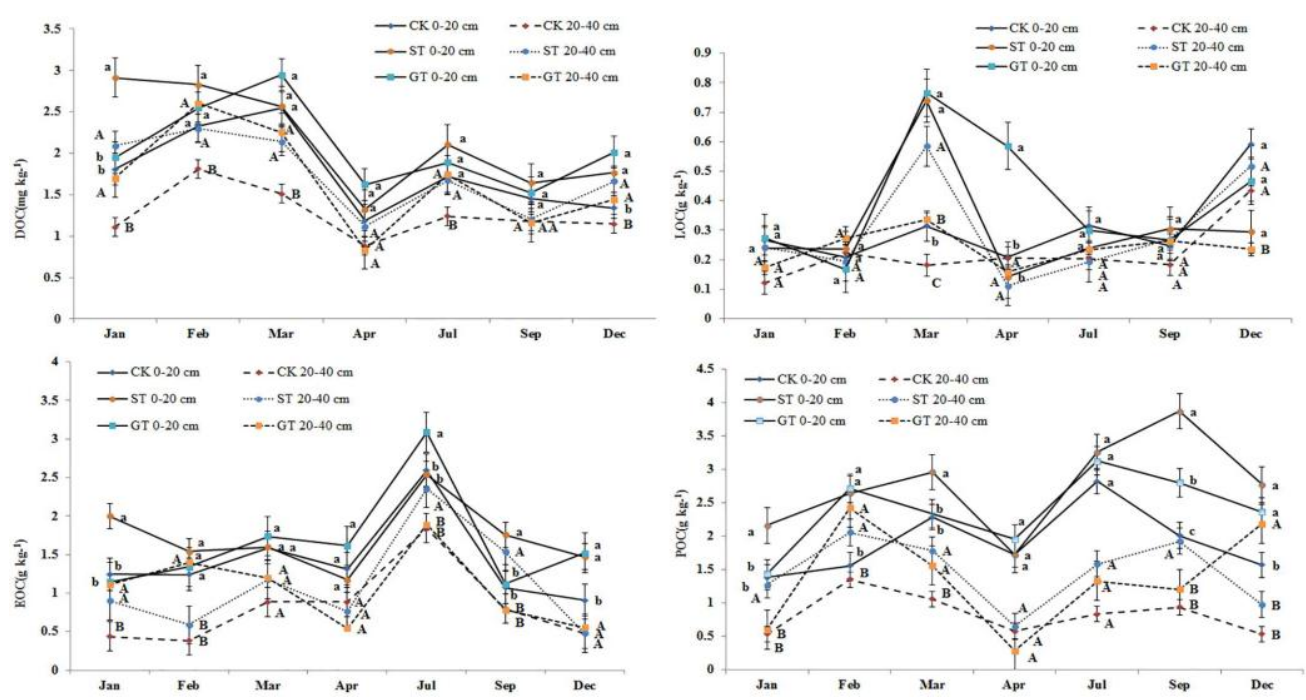

Fig.7a The mean weight diameter (MWD) of different tillage management and fertilization at $0-20$ and $20-40 \mathrm{~cm}$

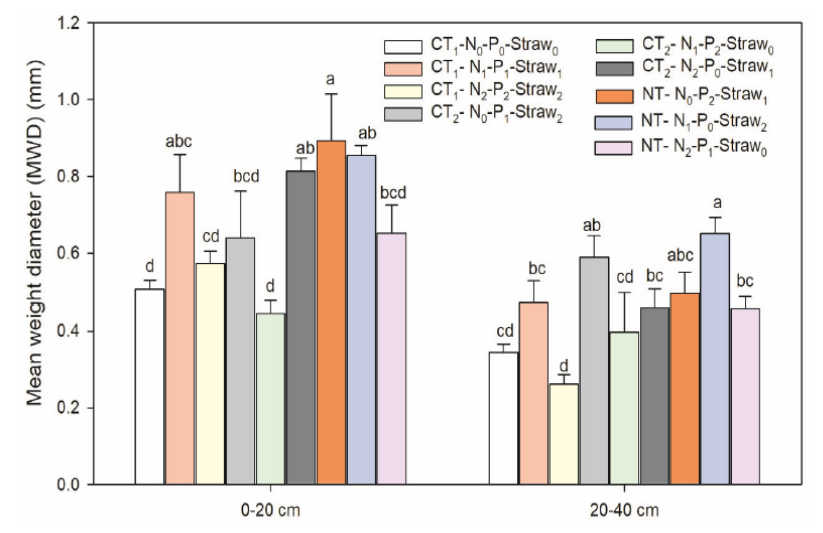

Fig.7b The geometric mean diameter (GWD) of different tillage management and fertilization at $0-20$ and $20-40 \mathrm{~cm}$

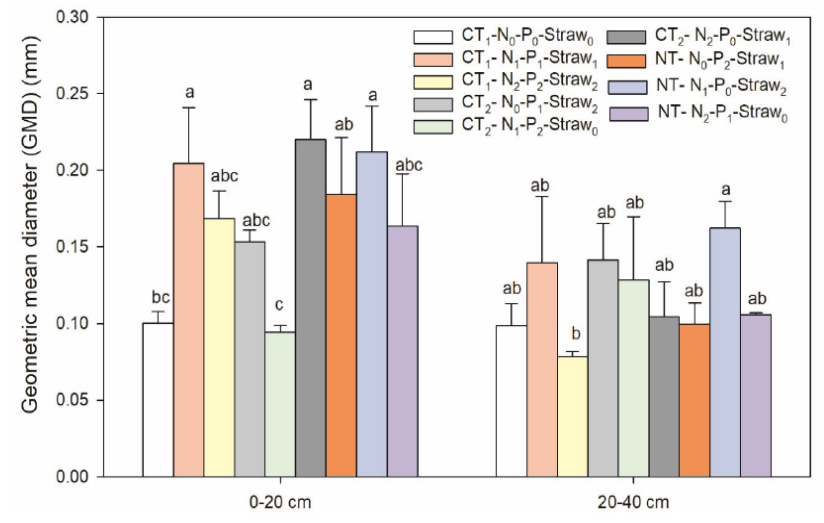


The effect of tillage and residue management on size distribution and stability of soil aggregates was clearly distinguishable. Irrespective of pre-treatment to the soil, NTNT provided a better soil aggregation. Crop residues on the surface protects the soil for the diurnal and seasonal changes in temperature, water content and aeration, and this maintains a good soil structural condition (Salem et al., 2015, Mondal et al., 2018).

The organic matter through decomposition of crop residues further promoted the stable aggregates formation in NT-NT, while physical disturbance and absence of crop residue in CT limits the formation and stabilization of soil aggregates (Jat et al., 2013; Naresh et al., 2017). Zhang et al., (2020) reported that aggregate stability decreased with the depth, as indicated by the mean weight diameter (MWD) and the geometric mean diameter (GWD) (Figures 7a $\& 7 b)$. In the surface layer, the treatment with straw-returning increased the MWD and GWD of soil aggregates by 16-50\% and 14.67-70.88\%, respectively, compared with the treatment without straw $\left(\mathrm{CT}_{1}-\mathrm{N}_{0}-\mathrm{P}_{0}-\mathrm{Straw}_{0}, \mathrm{CT}_{2}-\mathrm{N}_{1}-\mathrm{P}_{2}-\mathrm{Straw}_{0}\right.$, and NT-N $\left.-\mathrm{P}_{1}-\mathrm{Straw}_{0}\right)$.

Long-term applications of $\mathrm{N}$ and $\mathrm{P}$ fertilizer without straw did not significantly affect soil aggregate stability, as indicated by the similar MWD values in both surface and subsurface layers. However, the GWD of $\mathrm{CT}_{1}-\mathrm{N}_{0}-\mathrm{P}_{0}-\mathrm{Straw}_{0}$ and $\mathrm{CT}_{2}-\mathrm{N}_{1}-\mathrm{P}_{2}-\mathrm{Straw}_{0}$ treatments did not decrease at $20-40 \mathrm{~cm}$ depth soil (Fig.7b).

This may be attributed to the fact that no tillage decreased soil disturbance, facilitating the protection of soil organic matter from microbial degradation, which in turn favored the generation of physically stable LMAs and Mas, and increase the soil stability (Sarker et al., 2018)..

\section{Soil temperature}

Soil temperatures in surface layers can be significantly lower (often between 2 and $8^{\circ} \mathrm{C}$ ) during daytime (in summer) in zero tilled soils with residue retention compared to conventional tillage (Oliveira et al., 2001). Dahiya et al., (2007) compared the thermal regime of a loess soil during two weeks after wheat harvest between a treatment with wheat straw mulching, one with rotary hoeing and a control with no mulching and no rotary hoeing. Compared to the control, mulching reduced average soil temperatures by 0.74 , $0.66,0.58^{\circ} \mathrm{C}$ at 5,15 , and $30 \mathrm{~cm}$ depth respectively, during the study period. The rotary hoeing tillage slightly increased the average soil temperature by $0.21^{\circ} \mathrm{C}$ at $5 \mathrm{~cm}$ depth compared to the control. The tillage effect did no transmit to deeper depths. Gupta et al., (1983) also found that the difference between zero tillage with and without residue cover was larger than the difference between conventional tillage (mouldboard ploughing) and zero tillage with residue retention. Both mouldboard ploughing and zero tillage without residue cover had a higher soil temperature than zero tillage with residue cover, but the difference between mouldboard ploughing and zero tillage with residue cover was approximately one-third the difference between zero tillage with and without residue.

Naresh et al., (2015) reported that soil temperature at transplanting zone depth (5 $\mathrm{cm}$ ) during rice crop establishment was lower in 2009 than in 2010 and did not differ in the years 2010 to 2011. Treatments $T_{1}$ and $T_{2}$ reduced the mean maximum soil temperature at transplanting zone depth by 3.6 and $2.7^{\circ} \mathrm{C}$ compared to the treatment $\mathrm{T}_{3}$, respectively. Zero tillage reduced the impact of solar radiation by acting as a physical barrier resulting in lower soil temperature than the plough soil. The increased value of soil temperature for narrow raised beds was 
probably due to exposure of more surface area to the incident solar radiation in narrow raised beds than in flat conventional treatments. $T_{3}$ and $\mathrm{T}_{4}$ recorded higher soil temperature (mean of $38.4 \mathrm{~V} / \mathrm{S} 37.7^{\circ} \mathrm{C}$ ) compared to the flat treatments $\mathrm{T} 1, \mathrm{~T}_{2}$ and $\mathrm{T}_{5}$ at $15 \mathrm{DAT}$.

In conclusion the review study indicated that conservation tillage, especially no-tillage with straw-returning, improves soil structure, and change the size distribution of the aggregates. Soil aggregates are important agents of SOC retention and protection against decomposition. Quantity and quality of SOC fractions have an impact on soil aggregation that in turn physically protect the carbon from degradation by increasing the mean residence time of carbon. Soil management through the use of different tillage systems affects soil aggregation directly by physical disruption of the macro-aggregates, and indirectly through alteration of biological and chemical factors. Crop residue plays an important role in SOC sequestration, improving soil organic matter. Tillage reduction and residue retention both increased the proportion of soil organic matter as microbial biomass.

The findings also demonstrate the negative effect of conventional tillage not only on SOC decline, but also the weakening of soil aggregate formation and strength under continuous wet conditions, which can lead to other negative effects such as sediment loss and water quality concerns. The logical consequence is that the micro-aggregatewithin-macro-aggregate fraction shows promising potential for early detection of changes in soil $\mathrm{C}$ arising from changes in management. A greater percentage of carbon was found in all aggregate size classes with the conservation tillage treatments than $\mathrm{CT}$ at the 0 - to 5-cm depth. At the 10-15-cm depth, however, the highest carbon percentages were found in aggregates from the CT and RT treatments, again reflecting a probable lower deposition of carbon due to the NT treatment at the lower depth.

The organic carbon content under no-tillage and reduced tillage system increased compared to conventional tillage due to retention of residues and minimum disturbance in the former system. The notillage system showed a trend to accumulate organic carbon near the soil surface layer. Conventional tillage reduced soil organic $\mathrm{C}$ stocks and that of its labile fractions both in top and subsoil $(20-100 \mathrm{~cm})$. Reduced LOC fraction stocks in subsoil could partially be explained by the decrease in fine root biomass in subsoil, with consequences for SOC stock. However, not all labile fractions could be useful early indicators of SOC alterations due to tillage and residue management options. There were good relationships between cumulative levels of $\mathrm{C}$ input and macroaggregate-associated carbon and between cumulative levels of carbon input and associated fraction of silt and clay (53-um). Soil sequestration with organic carbon in $(0.25-0.1 \mathrm{~mm})$ fraction is the optimal longterm sequestration measure for both carbon and nitrogen.

The no-tillage method revealed a tendency towards accumulation of organic carbon below the base of the soil surface. Conventional tillage decreased the stocks of carbon organic soil and its labile fractions in both the top and the subsoil $(20-100 \mathrm{~cm})$. The reduction of $\mathrm{POC}$ in topsoil was mainly motivated by a decrease in fine POC, while DOC was mainly reduced in the subsoil. The LOC fractions also decreased to SOC ratios, suggesting a decline in carbon efficiency as a result of tillage and residue management. Reduced LOC fractional stocks in the subsoil may be partly explained by the decline in subsoil fine root biomass, with implications for SOC stocks. 


\section{References}

Al-Kaisi, M.M., Douelle, A., and KwawMensah, D. 2014. Soil micro-aggregate and macro-aggregate decay over time and soil carbon change as influenced by different tillage systems. J Soil Water Conserv., 69(6):574-580.

Bot, A., and Benites, J. 2005. The importance of soil organic matter key to droughtresistant soil and sustained crop production. FAO soils bulletin. 80p.

Bronick, C.J., and Lal, R. 2005. Soil structure and management: a review. Geodema, 124:3-22.

Calegari, A., Hargrove, W. L., Rheinheimer, D. D., Ralisch, R., Tessier, D., Tourdonnet, S., and Guimaraes, M. F. 2008. Impact of long-term no-tillage and cropping system management on soil organic carbon in an Oxisol: A model for sustainability. Agronomy J., 100 (4): 1013-1019.

Chen, H.Q., Marhan, S., Billen, N., and Stahr, K. 2009. Soil organic carbon and total nitrogen stocks as affected by different land uses. J Plant Nutr. Soil Sci.172:3242.

Chen, S., Xu, C., Yan, J., Zhang, X., Zhang, X., and Wang, D. 2016. The influence of the type of crop residue on soil organic carbon fractions: An11-year field study of rice-based cropping systems in southeast China. Agri Ecosyst Environ. 223:261269.

Christensen, B.T. 2001. Physical fractionation of soil and structural and functional complexity in organic matter turnover. Eur J Soil Sci., 52: 345-353.

Dahiya, R., Ingwersen, J., and Streck, T. 2007. The effect of mulching and tillage on the water and temperature regimes of a loess soil: Experimental findings and modeling. Soil Till. Res.96:52-63.

Das, T.K., Bhattacharyya, R., Sharma, A.R., Das, S., Saad, A.A., and Pathak H. 2013.Impacts of conservation agriculture on total soil organic carbon retention potential under an irrigated agro- ecosystem of the western Indo-Gangetic Plains. Eur. J. Agron. 51:34-42.

Denef, K., Zotarelli, L., Boddey, R.M., and Six, J. 2007. Micro-aggregate-associated carbon as a diagnostic fraction for management-induced changes in soil organic carbon in two Oxisols. Soil Biol Biochem. 39: 1165-1172.

Dhaliwal, J., Kukal, S.S., and Sharma, S.2018. Soil organic carbon stock in relation to aggregate size and stability under treebased cropping systems in Typic Ustochrepts. Agroforestry Syst., 92(2): 275-284.

Dou, X., He, P., Zhu, P., and Zhou, W. 2016. Soil organic carbon dynamics under longterm fertilization in a black soil of China: Evidence from stable $\mathrm{C}$ isotopes. Sci. Rep., 6:21488DO:10.1038/srep21488

Eynard, A., Schumacher, T.E., Lindstrom, M.J., and Malo, D.D. 2005. Effects of agricultural management systems on soil organic carbon in aggregates of Ustolls and Usterts. Soil Tillage Res.81:253-63.

Gale, W.J., Cambardella, C.A., and Bailey, T.B. 2000. Root-derived carbon and the formation and stabilization of aggregates. Soil Sci Soc Am J. 64: 201-207.

Gardenas, A.I., Agren, G.I., Bird, J.A., Clarholm, M., Hallin, S., Ineson, P., et al. 2011. Knowledge gaps in soil carbon and nitrogen interactions - from molecular to global scale. Soil Biol Biochem. 43: 702717.

Gu, C., Liu, Y., Mohamed, I., Zhang, R., Wang, X., Nie, X., et al. 2016. Dynamic Changes of Soil Surface Organic Carbon under Different Mulching Practices in Citrus Orchards on Sloping Land. PLoS ONE 11(12): e0168384.

Gunina, A., and Kuzyakov, Y. 2014. Pathways of litter $\mathrm{C}$ by formation of aggregates and SOM density fractions: implications from ${ }^{13} \mathrm{C}$ natural abundance. Soil Biol Biochem., 71:95-104.

Gupta, S.C., Larson, W.E., and Linden, D.R. 1983. Tillage and Surface Residue Effects on Soil Upper Boundary Temperatures. Soil Sci. Soc. Am. J. 47:1212-1218. 
Jardine, P.M., McCarthy, J.F., and Weber, N.L.1989. Mechanisms of dissolved organic carbon adsorption on soil. Soil Sci Soc Am J. 53(5): 1378-1385.

Jat, M., Gathala, M., Saharawat, Y., Tetarwal, J., and Gupta, R. 2013. Double no-till and permanent raised beds in maize-wheat rotation of North-Western Indo-Gangetic Plains of India: Effects on crop yields, water productivity, profitability and soil physical properties. Field Crops Res., 149: 291-299.

Jiang, X., Hu, Y., Bedell, JH. Xie, D., and Wright. 2011. Soil organic carbon and nutrient content in aggregate-size fractions of a subtropical soil under variable tillage. Soil Use Manag. 27(1): 28-35.

Johnson, J.M.F., Martinez, V.A., Cambardella, C.A., and Barbour, N.W. 2013. Crop and Soil Responses to Using Corn Stover as a Bioenergy Feedstock: Observations from the Northern US Corn Belt. Agriculture. 3(1):72-89.

Kaisi, A. M., and Yin, X. 2005. Tillage and crop residue effects on soil carbon and carbon dioxide emission in corn-soybean Rotations. J. Environ. Qual, 34: 437-445.

Khanal, N. P., Maharjan, K.L., and Dangol, D.R. 2012.Soil conservation practices for sustainability of rice-wheat system in Nepal: A Review. J Int Dev Coop., 18 (4): 11-20.

Kumar, A., Naresh, R.K.,Singh,S., Mahajan, N.C., and Singh, O. 2019. Soil Aggregation and Organic Carbon Fractions and Indices in Conventional and Conservation Agriculture under Vertisol soils of Sub-tropical Ecosystems: A Review. Int. J. Curr. Microbiol. App. Sci., 8(10): 2236-2253.

Ladha, J.K., Fischer, K.S., Hossain, M., Hobbs, P.R., and Hardy, B. 2000.Improving the productivity and sustainability of ricewheat systems of the Indo-Gangetic Plains: A synthesis of NARS-IRRI partnership research. Discussion Paper No. 40.

Mangalassery, S., Sjogersten, S., Sparkes, D.L.,
Sturrock, C.J., Craigon, J., and Mooney, S.J. 2014. To what extent can zero tillage lead to a reduction in greenhouse gas emissions from temperate soils? Sci Rep. 4: 4586 | DOI: 10.1038/srep04586

Meenakshi. 2016. Effect of long-term zero tillage in wheat on $\mathrm{C}$ and $\mathrm{N}$ fractions of different textured soils under rice-wheat cropping system. M.Sc. Soil Science Thesis Chaudhary Charan Singh Haryana Agricultural University, Hisar.

Meurer, K. H., Haddaway, N. R., Bolinder, M. A., and Kätterer, T. 2017. Tillage intensity affects total SOC stocks in boreo-temperate regions only in the topsoil-a systematic review using an ESM approach. Earth-Sci Rev., 177: 61322.

Mondal, S., Das, T.K., Thomas, P., Mishra, A.K., Bandyopadhyay, K.K., Pramila Aggarwal, P., and Chakraborty, D. 2019. Effect of conservation agriculture on soil hydro-physical properties, total and particulate organic carbon and root morphology in wheat (Triticum aestivum) under rice (Oryza sativa)-wheat system. Indian J Agri Sci., 89 (1): 46-55.

Mondal, S., Das, A., Pradhan, S., Tomar, R., Behera, U., Sharma, A., Paul, A., and Chakraborty, D. 2018. Impact of tillage and residue management on water and thermal regimes of a sandy loam soil under pigeon-pea-wheat cropping system. J Indian Soc Soil Sci., 66: 40-52.

Naresh, R.K., Gupta, Raj K., Gajendra Pal, Dhaliwal, S.S., Kumar, D., Kumar, V., Arya, V.K., Raju, Singh,S.P., Basharullah and Singh, O. 2015.Tillage crop establishment strategies and soil fertility management: resource use efficiencies and soil carbon sequestration in a rice-wheat cropping system. Eco. Env. \& Cons. 21:127-134.

Naresh, R.K., Timsina, J., Bhaskar, S., Gupta, R.K., Singh, A.K., Dhaliwal, S.S., et al. 2017. Effects of Tillage, Residue and Nutrient Management on Soil Organic Carbon Dynamics and its Fractions, Soil Aggregate Stability and Soil Carbon 
Sequestration: A Review. EC Nutrition. (12) 2:53-80.

Nascente, A.S., Li, Y., and Crusciol, C.A.C. 2015. Soil aggregation, organic carbon concentration, and soil bulk density as affected by cover crop species in a no-tillage system. Rev Bras Cienc Solo. 39:871-9.

Oliveira, J.C.M., Timm, L.C., Tominaga, T.T., Cassaro, F.A.M., et al. 2001. Soil temperature in a sugar-cane crop as a function of the management system. Plant Soil, 230:61-66.

Ou, H-P., Liu, X-H., Chen, Q-S., Huang, Y-F., He, M-J.,Tan, H-W., Xu, F-L., Li, Y-R., and $\mathrm{Gu}, \mathrm{M}-\mathrm{H}$. 2016. Water-Stable Aggregates and Associated Carbon in a Subtropical Rice Soil under Variable Tillage. Rev Bras Cienc Solo., v40:e0150145.

Parihar, C.M., Jat, S.L., Singh, A.K., Datta, A., Parihar, M.D., Varghase, E., Bandyopadhyay, K.K., Nayak, H.S., Kuri, B.R., and Jat, M.L. 2018. Changes in carbon pools and biological activities of a sandy loam soil under medium-term conservation agriculture and diversified cropping systems. Eur. J. Soil Sci., 69: 902-912.

Paudel, M., Sah, S.K., McDonald, A., and Chaudhary, N.K. 2014. Soil Organic Carbon Sequestration in Rice-Wheat System under Conservation and Conventional Agriculture in Western Chitwan, Nepal. World J Agri Res., 2 (6A): $1-5$

Prasad, K.S.K., Manduri Veerendra, Mahajan, N.C., Kancheti Mrunalini, Lingutla Sirisha, Reddy, T.V., and Naresh, R.K. 2019. Water-Stable aggregates and soil organic carbon fractions in a sub-tropical RWCS under variable tillage and precision nutrient management: A review. Int J Chem Stu., 7(3): 2228-2240.

Ratnayake, R.R., Roshanthan, T., Gnanavelrajah, N., and Karunaratne, S.B. 2019. Organic Carbon Fractions, Aggregate Stability, and Available
Nutrients in Soil and Their Interrelationships in Tropical Cropping Systems: A Case Study, Eurasian Soil Sci., 52(12):1542-1554.

Rattan, R. K., and Datta, S. P. 2011. Carbon sequestration and agricultural production in India. In: A. R. Sharma and U. K. Behera (eds). Resource conserving techniques in crop production (pp. 155165). Scientific publishers, India.

Regmi, A. P., Ladha J. K., Pathak, H., Pasuquin, E., Bueno, C., Dawe, D., Hobbs, P.R., Joshy, D., Maskey, S.L., and Pandey, S.P. 2003. Yield and soil fertility trends in a 20-year rice-ricewheat experiment. Better crops int., 17(2): 30-31.

Saljnikov, E., D. Cakmak, and S. Rahimgdieva. 2013. Soil organic matter stability as affected by land management in Steppe Ecosystem. INTECH Journals, Chapter 10, p.269-310.

Salem, H. M., Valero, C., Muñoz, M. Á., Rodríguez, M. G., and Silva, L. L. 2015. Short-term effects of four tillage practices on soil physical properties, soil water potential, and maize yield. Geoderma 237: 60-70.

Sarker, J.R., Singh, B.P., Cowie, A.L., Fang, Y., Collins, D., Badgery, W., and Dalal, R.C.2018. Agricultural management practices impacted carbon and nutrient concentrations in soil aggregates, with minimal influence on aggregate stability and total carbon and nutrient stocks in contrasting soils. Soil Tillage Res.178: 209-223.

Six, J., Elliott, E.T., and Paustian, K. 1998. Aggregate and Soil Organic Matter Dynamics under Conventional and NoTillage Systems. Soil Sci Soc Am J. 63(5):1350-1358.

Stirzaker, R., J.B. Passiourra, and Y. Wilms. 1996. Soil structure and plant growth: Impact of bulk density and biopores. Plant Soil, 185:151-162.

Tiwari, R.C., Verma, U.N., and Mishra, A.K. 1995. Effect of long-term cropping system on chemical characteristics of soil 
properties. J. Indian Soc. Soil sci., 43:278-279.

Vogelmann, E.S., Reichert, J.M., Prevedello, J., Awe, G.O., and Mataix-Solera, J. 2013. Can occurrence of soil hydrophobicity promote the increase of aggregates stability? Catena. 110:24-31.

Wander, M.M., and Yang, X. 2000. Influence of tillage on the dynamics of loose and occluded-particulate and humified organic matter fractions. Soil Biol Biochem. 32: 1551-1560.

Wang, C.Y., He, N.P., Zhang, J.J., Lv, Y.L., and Wen, L. 2015. Changes in soil organic matter composition and stability with grazing exclusion in Inner Mongolian grasslands. PloS ONE. 2015; 10: e0128837.

Wang, H., Wang, S., Zhang, Y., Wang, X., Wang, R., and Li, J. 2018. Tillage system change affects soil organic carbon storage and benefits land restoration on loess soil in North China. https://doi. org/10.1002/ldr.3015

Wiesmeier, M., Steffens, M., Mueller, C.W., Kolbl, A., Reszkowska, A., Horn, R., et al. 2012. Aggregate stability and physical protection of soil organic carbon in semiarid steppe soils. Eur J Soil Sci. 63: 22-
31

Xu, S.Q., Zhang, M. Y., Zhang, H.L., Chen, F., Yang, G.L., and Xiao, X.P. 2013. Soil organic carbon stocks as affected by tillage systems in a double-cropped rice field. Pedosphere.23 (5):696-704.

Zhao, H., Shar, A.G., Li, S., Chen, Y., Shi, J., Zhang, X., and Tian, X. 2018. Effect of straw return mode on soil aggregation and aggregate carbon content in an annual maize-wheat double cropping system. Soil Tillage Res.175:178-186.

Zhang, H., Lingan Niu, L., Hu, K., Hao, J., Li, F., Gao, Z., and Wang, X. 2020. Influence of Tillage, Straw-Returning and Mineral Fertilization on the Stability and Associated Organic Content of Soil Aggregates in the North China Plain. Agronomy, 10, 951; doi:10.3390/agronomy10070951

Zheng, H., Liu, W., Zheng, J., Luo, Y., Li, R., Wang, H., et al. 2018. Effect of long-term tillage on soil aggregates and aggregate associated carbon in black soil of Northeast China. PLoS ONE 13 (6): e0199523

\section{How to cite this article:}

Singh, S. P., R. K. Naresh, Yogesh Kumar and Robin Kumer. 2020. Effects of Conservation Agriculture and Temperature Sensitivity on Soil Organic Carbon Dynamics; its Fractions, and Soil Aggregate Stability in RWCS of Sub-tropical India: A Review. Int.J.Curr.Microbiol.App.Sci. 9(08): 658-675. doi: https://doi.org/10.20546/ijcmas.2020.908.073 